\title{
Trends in the management of gastric cancer over a 32-year period: a French population-based study
}

\author{
Elodie Herbreteau • Valérie Jooste • \\ Samia Hamza $\cdot$ Côme Lepage $\cdot$ Jean Faivre $\cdot$ \\ Anne-Marie Bouvier
}

Received: 18 December 2012/Accepted: 13 January 2014/Published online: 1 February 2014

(c) The International Gastric Cancer Association and The Japanese Gastric Cancer Association 2014

\begin{abstract}
Background Gastric cancer is still generating interest because of its poor prognosis. The aim of this study was to investigate time trends in diagnostic assessment, patterns of care, and survival of gastric cancers.

Methods We considered 5,010 gastric cancers diagnosed between 1976 and 2007 in a well-defined French population. Logistic regressions were used to identify factors associated with R0 resection and operative mortality. A multivariate relative survival analysis was performed.

Results Diagnostic modalities have changed. Since 1988, endoscopy is performed when gastric cancer is suspected $(95.5 \%)$. However, there has been no strong variation in stage over time: the proportion of stage I cancers increased from $5.5 \%$ to $13.4 \%$ between the periods 1976-1979 and 2004-2007 $(p<0.001)$ whereas that of advanced cases remained stable, $64.8 \%$ and $65.0 \%$, respectively. R0 resections rose from $36.7 \%(1976-1979)$ to $46.7 \%$ between 1980 and 1999, and decreased to $32.7 \%$ thereafter. Age, tumor location, and period were associated with R0 resection. Neoadjuvant and adjuvant chemotherapy were rarely used before 2000 , then reached $15.0 \%$ and $19.1 \%$, respectively, during the later period. Operative mortality after R0 resection decreased from $18.3 \%$ during the 1976-1979 period to $4.3 \%$ during the 2004-2007 period $(p<0.001)$. Prognosis slightly improved during the three first periods, from $13.0 \%$ to $22.6 \%$, then leveled off,
\end{abstract}

E. Herbreteau · V. Jooste $\cdot$ S. Hamza $\cdot$ C. Lepage $\cdot$ J. Faivre

A.-M. Bouvier $(\square)$

Digestive Cancer Registry of Burgundy INSERM U866,

University Hospital, University of Burgundy, BP 87 900,

21079 Dijon Cedex, France

e-mail: anne-marie.bouvier@u-bourgogne.fr not exceeding $26.0 \%$ thereafter. Stage, age, histology, and time period significantly influenced survival.

Conclusion Changes in diagnostic modalities were associated with minor changes in stage and prognosis for gastric cancer. Earlier diagnosis and new therapeutic strategies are the best way to improve the prognosis.

Keywords Gastric cancer - Patterns of care - Survival . Population-based registry

\section{Introduction}

In spite of its declining incidence in most Western countries since the 1950s, gastric cancer remains relatively frequent, accounting for nearly $20 \%$ of all digestive tract cancers diagnosed in the European Union [1]. In France, it decreased considerably between 1980 and 2005, with an annual variation of $-2.3 \%$ in men and $-2.8 \%$ in women [2]. In contrast to this comforting trend in incidence, gastric cancer remains a highly fatal disease whose prognosis has improved little over time [3]. R0 resection remains the reference treatment, but numerous adjuvant chemotherapy protocols, associated or not with radiotherapy, have emerged in recent years [4]. Numerous improvements have been made in postoperative resuscitation and nonsurgical treatments. The impact of all these changes in the population at large is not well known. Data provided by specialized centers cannot be used as a reference because of unavoidable selection bias. Population-based studies that include all cases arising in a well-defined population are the best way to assess real changes in the management of gastric cancer. Such studies are rare because they require accurate and detailed data collection over a sufficiently long period of time. Thus, the objective of this study was to 
draw a picture of time trends in diagnostic strategy, treatment, and prognosis of gastric cancers diagnosed during the period 1976-2007 in a nonselected community-based series of patients in France.

\section{Population and methods}

\section{Material}

A population-based cancer registry records all digestive tract cancers in two administrative areas in France (Côted'Or and Saône-et-Loire, Burgundy, France). The registry covers a population of 1,050,000 inhabitants according to the 1999 census. Information was collected from multiple sources: pathology laboratories, university hospitals (including the Cancer Centre), general hospitals, private surgeons, gastroenterologists and oncologists, general practitioners, National Health Services data, and death certificates. Because they are somewhat unreliable, death certificates were only used to identify missing cases. Because of the multiplicity of information sources, we assumed that nearly all newly diagnosed cases were recorded. The quality and completeness of the registry is certified every 4 years through an audit carried out by the National Institute for Health and Medical Research (INSERM) and of the National Public Health Institute (InVS). All gastric cancers diagnosed during the 1976-2007 period were considered for this study.

Four categories were assigned for age: under 65, 65-74, 75-84, and over 85 years. The period of diagnosis was categorized into eight periods of 4 years. Morphological diagnostic examinations were recorded: contrast X-ray, endoscopy, ultrasonography (US), computed tomography scanner (CT-scan), or laparotomy. Diagnosis criteria were unknown in 6 cases. The site and morphology were coded according to the International Classification of Diseases (ICD-O3) [5]. Tumor location included cardia (C16.0), fundus (C16.1), corpus (C16.2), antrum and pylorus (C16.3, C16.4), and extension to more than one site (C16.8). The gastric location was not otherwise specified (C16.9) for 317 patients (6.3\%). Morphology was registered according to the conclusion of the pathological report related either to the surgical specimen or to the endoscopic biopsy. Morphology included adenocarcinoma ( $n=3,366)$, signet-ring cell cancers $(n=600)$, undifferentiated carcinoma $(n=418)$, lymphoma $(n=261)$, gastrointestinal stromal tumor $(n=48)$, sarcoma $(n=27)$, malignant digestive endocrine tumours $(n=35)$, and squamous cell cancers $(n=9)$. In 240 cases, the diagnosis was not histologically verified, but made from operative findings or medical imaging. In 6 cases the morphology was not notified in the database of the registry. Treatments were divided into R0 resection: macroscopic resection of all malignant tissue and no microscopic evidence of surgical margin involvement ( $n=2,149)$; R1/R2 resection: palliative resection $(n=547)$, surgical, or medical bypass $(n=412)$; and laparotomy alone $(n=214)$. Extended lymph node dissection for patients resected for cure was approximated by the number of resected nodes into D0/1 resection for cases with fewer than 25 nodes removed and D2 resection for cases with at least 25 nodes removed [6].

A total of 1,688 patients did not undergo surgery. Among patients who were not resected for cure $(n=2,862), 20.7 \%(n=593)$ received chemotherapy [of whom $18.2 \%(108 / 593)$ had combined radiotherapy], $2.8 \%$ received radiotherapy alone $(n=81)$, and $41.4 \%$ received best supportive care $(n=1,186)$. Cancer cases were classified according to the TNM classification, 7th revision [stage I: cancers limited to the gastric wall (T1/2 N0 M0); stage II: involvement of serosa and locoregional extension (T3/4 N0 M0); stage III: lymph node metastases (all T, N1/2 M0); and stage IV: visceral metastasis (M1)]. Nonresected cancers with no evidence of visceral metastasis were grouped with stage IV and classified as advanced cases. Those who underwent resection but were not staged were classified as unknown $(n=93,1.9 \%)$. Operative mortality was defined as death within 30 days of surgery. Five-year relative survival was calculated for patients diagnosed between 1976 and 2005; thus, the last period included in the survival analysis was a 2 -year period. Vital status at 5 years was known for $97.9 \%$ of these patients $(4,612 / 4,710)$.

\section{Statistics}

The association between categorical data was analyzed using the chi-square test. Time trends were established by 4-year periods by means of logistic models. Nonconditional logistic regressions were performed to identify factors independently associated with the probability of resection for cure and with operative mortality. The significance of the covariates was tested by the likelihood ratio test. Relative survival rates, defined as the ratio of the observed survival rate in the cancer patients under study to the expected survival rate in a population with similar gender and age distribution, were calculated. Relative survival reflects the excess mortality in cancer patients relative to background mortality. Multiple regression of relative survival was performed using a generalized linear model with a Poisson error structure based on collapsed data using exact survival times as proposed by Dickman et al. [7]. The significance of the covariates was tested using the likelihood ratio test. The analyses were performed using STATA, release 11 (STATA, College Station, TX, USA). 


\section{Results}

Over the study period, a total of 5,010 patients with gastric cancer were recorded, of whom $63.9 \%$ were men. The mean age at diagnosis was 70.7 years (SD, 12.6) for men and 75.2 years $(\mathrm{SD}, 12.3)$ for women $(p=0.001)$.

Diagnostic modalities changed over time. The use of endoscopy greatly increased until the 1988-1991 period, and then levelled off at around $95 \%$ in the $2000 \mathrm{~s}$ (Table 1). The proportion of patients only having X-ray examinations decreased from $23.2 \%$ (1976-1979) to $0.6 \%$ (2004-2007) ( $p$ for trend, <0.001).

The proportion of histologically verified cases rose from $80.4 \%$ to $98.1 \%$ between the first and last periods ( $p$ for trend, <0.001) (Table 1). During the 1976-1979 period, this proportion varied with age: $95.1 \%$ for patients under $65,85.7 \%$ for patients aged 65-74 years, $72.2 \%$ for patients aged 75-84 years, and $51.1 \%$ for patients over 85 years $(p<0.001)$. During the 2004-2007 period, the proportion of histologically verified cases no longer varied with age, accounting for $98.7 \%, 98.1 \%$, $98.7 \%$, and $95.8 \%$, respectively $(p=0.188)$. Among histologically verified cases, there was an increase in the proportion of signet-cell carcinomas [mean 4-year period variation of $+11.4 \%$ CI $(7.2 ; 15.5), p<0.001]$ and of lymphoma [mean 4-year period variation of $+11.1 \% \mathrm{CI}$ (5.0; 17.1), $p<0.001]$, and a decrease in the proportion of undifferentiated carcinomas [mean 4-year period variation of $-13.5 \% \mathrm{CI}(-19.2 ; 7.9), p<0.001]$. The proportion of adenocarcinomas was stable. Cancers located in the cardia showed the greatest increase in percentages over time, from $11.3 \%$ to $29.2 \%$, corresponding to a mean 4-year period variation of $+17.4 \%$ CI $(13.9 ; 20.8)$ $(p<0.001)$. At the same time, gastric cancers overlapping more than one site decreased from $17.1 \%$ to $3.9 \%$ $[-23.2 \%$ by 4-year time period CI $(-28.1 ;-18.3)$, $p<0.001]$.

There was no strong variation in stage at diagnosis over the time period. The most noteworthy event was the increase in early stage I cancers, which rose from $5.5 \%$ to $13.4 \%$ between the first and last periods. The corresponding mean 4-year period variation was $+7.8 \%$ [CI (3.7; 12.0), $p<0.001]$ (Table 2). The proportion of advanced cases did not change over time: it was $64.8 \%$ during the 1976-1979 period and $65.0 \%$ during the 2004-2007 period.

Table 1 Diagnostic procedures and epidemiologic characteristics of gastric cancers (\%)

\begin{tabular}{|c|c|c|c|c|c|c|c|c|}
\hline$N$ & $\begin{array}{l}1976-1979 \\
327\end{array}$ & $\begin{array}{l}1980-1983 \\
542\end{array}$ & $\begin{array}{l}1984-1987 \\
784\end{array}$ & $\begin{array}{l}1988-1991 \\
710\end{array}$ & $\begin{array}{l}1992-1995 \\
713\end{array}$ & $\begin{array}{l}1996-1999 \\
685\end{array}$ & $\begin{array}{l}2000-2003 \\
609\end{array}$ & $\begin{array}{l}2004-2007 \\
640\end{array}$ \\
\hline \multicolumn{9}{|l|}{ Diagnostic procedure } \\
\hline X-ray & 23.2 & 9.0 & 3.6 & 2.1 & 1.1 & 0.6 & 0.5 & 0.6 \\
\hline Endoscopy & 3.4 & 28.0 & 49.7 & 71.7 & 76.6 & 80.3 & 83.9 & 83.8 \\
\hline X-ray + endoscopy & 70.0 & 58.1 & 40.9 & 22.4 & 20.3 & 16.5 & 11.5 & 10.6 \\
\hline Surgery & 1.8 & 4.1 & 4.5 & 3.1 & 1.8 & 2.5 & 3.1 & 3.9 \\
\hline US or CT scan & 0.3 & 0.0 & 0.3 & 0.1 & 0.0 & 0.2 & 1.0 & 0.9 \\
\hline Other & 1.2 & 0.7 & 1.0 & 0.6 & 0.1 & 0.0 & 0.0 & 0.2 \\
\hline \multicolumn{9}{|l|}{ Histology } \\
\hline Adenocarcinoma & 62.1 & 71.8 & 69.3 & 68.0 & 70.1 & 67.7 & 71.9 & 65.2 \\
\hline Signet-ring cell & 8.6 & 6.1 & 10.0 & 13.4 & 11.1 & 16.6 & 12.6 & 15.3 \\
\hline Lymphoma & 2.5 & 3.0 & 3.6 & 6.2 & 5.8 & 8.5 & 4.4 & 6.1 \\
\hline Undifferentiated carcinoma & 5.2 & 8.9 & 9.1 & 7.2 & 6.0 & 2.3 & 2.3 & 5.8 \\
\hline Other $^{\mathrm{a}}$ & 3.7 & 3.5 & 4.2 & 6.9 & 8.4 & 10.8 & 8.6 & 11.9 \\
\hline No histology & 19.6 & 5.9 & 5.6 & 3.2 & 3.7 & 2.2 & 3.9 & 1.9 \\
\hline \multicolumn{9}{|l|}{ Location } \\
\hline Cardia & 11.3 & 13.5 & 15.3 & 15.9 & 16.4 & 22.8 & 26.9 & 29.2 \\
\hline Fundus & 9.8 & 8.3 & 7.5 & 9.9 & 10.2 & 10.4 & 14.6 & 10.8 \\
\hline Corpus & 21.1 & 21.6 & 25.0 & 17.8 & 20.9 & 20.6 & 19.1 & 20.0 \\
\hline Antrum and pylorus & 31.8 & 39.1 & 33.0 & 34.2 & 38.6 & 35.9 & 31.5 & 33.6 \\
\hline More than one site & 17.1 & 12.0 & 11.5 & 11.6 & 7.2 & 5.3 & 4.4 & 3.9 \\
\hline $\operatorname{NOS}^{\mathrm{b}}$ & 8.9 & 5.5 & 7.7 & 10.7 & 6.7 & 5.1 & 3.5 & 2.5 \\
\hline
\end{tabular}

${ }^{a}$ Gastrointestinal stromal tumors: 48 cases, sarcoma: 27 cases, malignant digestive endocrine tumours: 35 cases, squamous cell cancers: 9 cases, histology unknown: 6 cases

${ }^{\mathrm{b}}$ Location not otherwise specified; $6.3 \%(n=315)$ 
Table 2 Trends in stage at diagnosis and management of gastric cancers (\%)

\begin{tabular}{|c|c|c|c|c|c|c|c|c|}
\hline & 1976-1979 & 1980-1983 & 1984-1987 & 1988-1991 & 1992-1995 & 1996-1999 & 2000-2003 & 2004-2007 \\
\hline \multicolumn{9}{|l|}{ Stage at diagnosis } \\
\hline TNM I & 5.5 & 7.9 & 11.6 & 10.1 & 14.7 & 11.1 & 11.5 & 13.4 \\
\hline TNM II & 13.5 & 12.0 & 10.5 & 12.0 & 10.1 & 9.2 & 7.7 & 10.6 \\
\hline TNM III & 16.2 & 18.8 & 18.9 & 18.0 & 17.7 & 18.1 & 14.1 & 10.9 \\
\hline Advanced $^{\mathrm{a}}$ & 64.8 & 61.3 & 59.1 & 59.9 & 57.5 & 61.7 & 66.7 & 65.0 \\
\hline \multicolumn{9}{|l|}{ Surgical treatment } \\
\hline R0 resection & 36.7 & 47.8 & 48.2 & 47.2 & 46.1 & 44.0 & 35.6 & 32.7 \\
\hline D2 resection $^{\mathrm{b}}$ & 0.8 & 1.6 & 3.5 & 3.7 & 3.4 & 8.4 & 10.1 & 10.0 \\
\hline $\mathrm{R} 1 / \mathrm{R} 2$ resection & 8.0 & 9.6 & 10.0 & 11.4 & 11.4 & 8.5 & 13.3 & 14.2 \\
\hline Bypass, laparotomy & 15.9 & 13.8 & 13.5 & 10.1 & 12.4 & 12.8 & 12.6 & 10.6 \\
\hline No surgery & 39.5 & 28.8 & 28.3 & 31.3 & 30.2 & 34.7 & 38.4 & 42.5 \\
\hline \multicolumn{9}{|l|}{ Resection procedure } \\
\hline Total/extended gastrectomy & 28.8 & 37.9 & 39.0 & 39.2 & 42.4 & 44.3 & 40.9 & 35.7 \\
\hline Partial gastrectomy & 7.5 & 5.1 & 6.1 & 8.2 & 5.6 & 8.9 & 9.1 & 11.0 \\
\hline Subtotal gastrectomy & 61.0 & 56.3 & 53.5 & 51.2 & 51.2 & 45.1 & 47.0 & 53.3 \\
\hline \multicolumn{9}{|l|}{ Adjuvant chemotherapy } \\
\hline Preoperative & 0.0 & 0.0 & 0.5 & 0.6 & 1.2 & 5.3 & 14.8 & 15.8 \\
\hline Postoperative & 10.8 & 5.4 & 3.7 & 5.4 & 6.8 & 9.3 & 8.3 & 19.1 \\
\hline Palliative chemotherapy & 8.3 & 7.6 & 5.3 & 12.0 & 18.4 & 28.8 & 32.9 & 43.4 \\
\hline Radiotherapy & 1.5 & 3.4 & 2.2 & 2.7 & 5.6 & 7.3 & 11.4 & 14.5 \\
\hline
\end{tabular}

a TNM stage IV cancer cases and nonresected cancers with no evidence of visceral metastasis

${ }^{\mathrm{b}}$ Defined as more than 25 lymph nodes removed during the R0 resection

There was no great variation in the surgical treatment of gastric cancers. After an initial brief increase between the first and second periods, R0 resections were performed in $46.7 \%$ of cases between 1980 and 1999, and then decreased to $34.1 \%$ of cases between 2000 and 2007. The proportion of R0 resection with extended D2 lymph node dissection rose from $0.8 \%$ to $8.3 \%$ between the first and the sixth period, then leveled off at $10 \%$ between 2000 and 2007. Opposite trends were observed for the proportion of patients not receiving surgery. There was no significant variation in the proportion of palliative resections and other surgical procedures.

Table 3 shows the proportion of patients undergoing R0 resection by sex, age, site, and period of diagnosis, and the corresponding multivariate estimates of odds ratio. Age, location, and period of diagnosis were significantly and independently associated with R0 resection. The probability of R0 resection was 5.3 times less for patients aged 85 years and over than for patients aged under 65 years. Independently of other studied factors, the period of diagnosis was associated with the probability of resection for cure. As compared to the 1976-1979 period, the likelihood of having a resection for cure increased until the 1996-1999 period and significantly decreased thereafter. $\mathrm{R} 0$ resection was performed more often in cancer of the antrum and pylorus than in cancer of other sites.
Neoadjuvant chemotherapy was hardly ever used before 2000. It then reached $15 \%$ during the last two study periods. Adjuvant chemotherapy was performed in slightly less than $10 \%$ of patients, except during the last study period when it reached $19.1 \%$. Neoadjuvant radiotherapy was also little used before 2000 . Only $15.7 \%$ of patients with R0 resection during the 2000-2003 period and $17.2 \%$ during the 2004-2007 period received this therapy. Palliative chemotherapy was rarely used until $1992(8.1 \%)$. It then increased to $18.4 \%(1992-1995)$ and then to $43.4 \%$ (2004-2007). Radiotherapy was also used as a palliative treatment. It was rarely used until 2000, when it was slightly over $10 \%$.

Operative mortality for R0 resection decreased from $18.3 \%$ for the $1976-1979$ period to $4.3 \%$ for the 2004-2007 period $(p<0.001)$ (Table 4). The mean 4-year period variation was $-17.9 \%$ CI $(-24.8 ;-11.2)$ $(p<0.001)$. The effects of sex, age, period of diagnosis, and location on operative mortality after $\mathrm{R} 0$ resection were analyzed using a regression method. Age was an important factor associated with operative mortality: patients aged 85 years and over were nearly six times more likely to die during the postoperative phase than patients under 65 . There was a 6.7-fold decrease in the likelihood of operative mortality between the first and the last study periods. Cancer site was also an important determinant of operative 
Table 3 Factors associated with resection for cure (logistic regression model) a Likelihood ratio test

${ }^{\mathrm{b}}$ Location not otherwise specified: 53 cases

\begin{tabular}{|c|c|c|c|c|c|}
\hline & Number of patients & R0 resection (\%) & Adjusted odds ratio & {$[95 \% \mathrm{CI}]$} & $p^{\mathrm{a}}$ \\
\hline \multicolumn{6}{|l|}{ Sex } \\
\hline Male & 1,743 & 43.3 & 1 & & \\
\hline Female & 967 & 42.2 & 0.93 & {$[0.82-1.06]$} & 0.278 \\
\hline \multicolumn{6}{|l|}{ Age at diagnosis } \\
\hline$<65$ years & 1,161 & 52.7 & 1 & & \\
\hline $65-74$ years & 1,393 & 48.6 & 0.83 & {$[0.70-0.97]$} & 0.022 \\
\hline $75-84$ years & 1,685 & 42.0 & 0.60 & {$[0.51-0.70]$} & 0.000 \\
\hline$\geq 85$ years & 771 & 19.6 & 0.19 & {$[0.15-0.24]$} & 0.000 \\
\hline \multicolumn{6}{|l|}{ Period at diagnosis } \\
\hline 1976-1979 & 327 & 36.7 & 1 & & \\
\hline $1980-1983$ & 542 & 47.8 & 1.47 & [1.10-1.98] & 0.010 \\
\hline 1984-1987 & 784 & 48.2 & 1.62 & [1.23-2.14] & 0.001 \\
\hline 1988-1991 & 710 & 47.2 & 1.72 & [1.29-2.28] & 0.000 \\
\hline 1992-1995 & 713 & 46.1 & 1.52 & [1.14-2.02] & 0.004 \\
\hline 1996-1999 & 685 & 44.0 & 1.43 & [1.08-1.91] & 0.014 \\
\hline 2000-2003 & 609 & 35.6 & 1.02 & {$[0.76-1.37]$} & 0.889 \\
\hline 2004-2007 & 640 & 32.7 & 0.82 & {$[0.61-1.10]$} & 0.188 \\
\hline \multicolumn{6}{|l|}{ Location } \\
\hline Cardia & 967 & 34.5 & 1 & & \\
\hline Fundus & 508 & 35.8 & 1.06 & [0.84-1.34] & 0.620 \\
\hline Corpus & 1,042 & 47.7 & 1.73 & [1.43-2.08] & 0.000 \\
\hline Antrum and pylorus & 1,746 & 52.5 & 2.28 & [1.91-2.70] & 0.000 \\
\hline More than one site & 432 & 39.1 & 1.10 & {$[0.86-1.40]$} & 0.468 \\
\hline $\operatorname{NOS}^{\mathrm{b}}$ & 315 & 16.2 & 0.35 & {$[0.25-0.48]$} & 0.000 \\
\hline
\end{tabular}

mortality. The likelihood of postoperative death was twice as high for cancer of the cardia and cancer overlapping two contiguous sites as for cancer of other sites. Gender was not a significant factor.

Overall 5-year relative survival rose from $13.0 \%$ during the 1976-1979 period to $22.6 \%$ during the 1984-1987 period, then remained stable during the last five time periods (Table 5). Survival did not increase much over time for stage I and II cancers, whereas it doubled for stage III between the first and the last period and remained stable for advanced gastric cancers (Table 6). Five-year relative survival for the studied variables and the corresponding multivariate relative survival analysis are given in Table 5. Sex did not influence survival. Five-year relative survival increased after R0 resection from $34.5 \%$ during the first period to $52.5 \%$ during the last one. The survival after extended D2 lymph node dissection among these patients was $56.2 \%$ between 1996 and 2007. Stage at diagnosis was the strongest prognostic factor. The excess hazard ratio of death was 20 times higher in advanced cancers than in TNM stage I cancers. Age, period of diagnosis, and histology were also independent prognostic factors. After adjusting for these variables, location was no longer a strong prognostic factor.

\section{Discussion}

The data presented here are important in that they report the management of gastric cancer at a population level over 32 years. One of the major problems faced by populationbased studies is to determine the completeness and reliability of data. Given the number and variety of information sources, we assumed that nearly all newly diagnosed cases of gastric cancer were recorded. Information on diagnostic assessment subsite, morphology, treatment, and stage at diagnosis was almost complete. The study was therefore carried out without selection bias.

Among the major findings that emerged from this study was the change in the diagnostic assessment of gastric cancer. No comparable population-based data are available in the literature. The proportion of gastric cancers with histology as the diagnostic criterion increased over the study period; this was related to the development of endoscopy, which progressively became the only diagnostic tool whatever the age. The discrepancies resulting from age observed at the beginning of the study period had completely disappeared at the end of the study. Changes in diagnostic strategies were not associated with a major improvement in stage at diagnosis. The proportion of 
Table 4 Factors associated with postoperative mortality after $\mathrm{R} 0$ resection (logistic regression)

\footnotetext{
a Likelihood ratio test

${ }^{\mathrm{b}}$ Location not otherwise specified
}

\begin{tabular}{|c|c|c|c|c|c|}
\hline & $\begin{array}{l}\text { Number of } \\
\text { patients }\end{array}$ & $\begin{array}{l}\text { Operative mortality } \\
(\%)\end{array}$ & $\begin{array}{l}\text { Adjusted odds } \\
\text { ratio }\end{array}$ & {$[95 \% \mathrm{CI}]$} & $p^{\mathrm{a}}$ \\
\hline \multicolumn{6}{|l|}{ Sex } \\
\hline Male & 1,385 & 8.5 & 1 & & \\
\hline Female & 764 & 10.2 & 1.33 & {$[0.96-1.85]$} & 0.086 \\
\hline \multicolumn{6}{|l|}{ Age at diagnosis } \\
\hline$<65$ years & 612 & 4.7 & 1 & & \\
\hline $65-74$ years & 678 & 8.7 & 1.89 & [1.18-3.01] & 0.008 \\
\hline $75-84$ years & 708 & 13.6 & 3.76 & {$[2.41-5.88]$} & 0.000 \\
\hline$\geq 85$ years & 151 & 15.2 & 5.68 & [3.07-10.50] & 0.000 \\
\hline \multicolumn{6}{|c|}{ Period at diagnosis } \\
\hline 1976-1979 & 120 & 18.3 & 1 & & \\
\hline 1980-1983 & 259 & 15.4 & 0.72 & {$[0.40-1.31]$} & 0.285 \\
\hline 1984-1987 & 378 & 9.8 & 0.38 & {$[0.21-0.70]$} & 0.002 \\
\hline 1988-1991 & 335 & 6.9 & 0.26 & {$[0.14-0.50]$} & 0.000 \\
\hline 1992-1995 & 329 & 9.1 & 0.36 & {$[0.20-0.68]$} & 0.001 \\
\hline 1996-1999 & 302 & 9.3 & 0.35 & {$[0.19-0.66]$} & 0.001 \\
\hline 2000-2003 & 217 & 8.3 & 0.30 & {$[0.15-0.61]$} & 0.001 \\
\hline 2004-2007 & 209 & 4.3 & 0.15 & {$[0.07-0.35]$} & 0.000 \\
\hline \multicolumn{6}{|l|}{ Location } \\
\hline Cardia & 334 & 13.5 & 1 & & \\
\hline Fundus & 182 & 7.7 & 0.48 & {$[0.25-0.91]$} & 0.025 \\
\hline Corpus & 497 & 7.8 & 0.46 & [0.29-0.73] & 0.001 \\
\hline $\begin{array}{l}\text { Antrum and } \\
\text { pylorus }\end{array}$ & 916 & 8.5 & 0.42 & [0.28-0.64] & 0.000 \\
\hline $\begin{array}{l}\text { More than one } \\
\text { site }\end{array}$ & 169 & 17.8 & 1.01 & [0.59-1.74] & 0.959 \\
\hline $\mathrm{NOS}^{\mathrm{b}}$ & 51 & 2.0 & 0.09 & [0.01-10.71] & 0.022 \\
\hline
\end{tabular}

The results concerning $\mathrm{R} 0$ resection are disappointing. This is currently the only treatment for cure. After an increase in R0 resection between the second and sixth study periods, the proportion of R0 resections returned to the level of the first period. Similar results were reported in the USA and Europe [14, 15]. Data from the Surveillance, Epidemiology and End Results registries indicate a decline of $6 \%$ in the resection of non-cardia gastric cancers between 1983 and 2002 [15]. In the Netherlands, between 1990 and 2007, resection rates remained at a high level among patients with non-cardia gastric cancer, whereas they decreased among stage I, II, and IV patients with cardia cancer [14]. More careful selection of patients who undergo surgery is an explanation. Improved imaging modalities can lead to better preoperative staging. This hypothesis is supported by the fact that the decrease in $\mathrm{R} 0$ resection during the last two periods studied was not associated with a decrease in stage I cancers or in 5-year survival.

One of the most obvious trends lies in the reduction in operative mortality, particularly after R0 resection. This trend may be attributable to improved surgical techniques, 
Table 5 Prognostic factors for gastric cancers
Multivariate relative survival model (Dickman model)

${ }^{\text {a }}$ Likelihood ratio test

b Gastrointestinal stromal tumors, sarcoma, malignant digestive endocrine tumour, squamous cell cancers, and histology unknown

${ }^{c}$ Location not otherwise specified

\begin{tabular}{|c|c|c|c|c|}
\hline & 5-year relative survival $(\%)$ & HR & {$[95 \% \mathrm{CI}]$} & $p^{\mathrm{a}}$ \\
\hline \multicolumn{5}{|l|}{ Sex } \\
\hline Male & 21.2 & 1 & & \\
\hline Female & 23.5 & 0.98 & {$[0.89-1.08]$} & 0.682 \\
\hline \multicolumn{5}{|l|}{ Age at diagnosis } \\
\hline$<65$ years & 32.4 & 1 & & \\
\hline $65-74$ years & 23.7 & 1.19 & [1.06-1.33] & 0.002 \\
\hline $75-84$ years & 16.0 & 1.69 & [1.51-1.89] & 0.000 \\
\hline$\geq 85$ years & 11.5 & 2.39 & {$[2.01-2.84]$} & 0.000 \\
\hline \multicolumn{5}{|l|}{ Period at diagnosis } \\
\hline $1976-1979$ & 13.0 & 1 & & \\
\hline $1980-1983$ & 19.1 & 0.88 & [0.72-1.09] & 0.245 \\
\hline 1984-1987 & 22.6 & 0.79 & {$[0.65-0.96]$} & 0.018 \\
\hline 1988-1991 & 23.4 & 0.71 & {$[0.58-0.87]$} & 0.001 \\
\hline 1992-1995 & 20.8 & 0.82 & {$[0.67-0.99]$} & 0.046 \\
\hline 1996-1999 & 24.9 & 0.73 & {$[0.60-0.89]$} & 0.002 \\
\hline $2000-2003$ & 23.5 & 0.64 & {$[0.52-0.78]$} & 0.000 \\
\hline 2004-2005 & 25.7 & 0.64 & {$[0.51-0.80]$} & 0.000 \\
\hline \multicolumn{5}{|l|}{ Stage at diagnosis } \\
\hline TNM I & 82.3 & 1 & & \\
\hline TNM II & 42.4 & 4.23 & {$[3.11-5.76]$} & 0.000 \\
\hline TNM III & 21.5 & 7.17 & {$[5.36-9.59]$} & 0.000 \\
\hline Advanced & 3.4 & 20.74 & [15.59-27.59] & 0.000 \\
\hline \multicolumn{5}{|l|}{ Histology } \\
\hline Adenocarcinoma & 21.2 & 1 & & \\
\hline Signet-ring cell & 22.9 & 1.10 & {$[0.97-1.26]$} & 0.115 \\
\hline Lymphoma & 58.0 & 0.46 & {$[0.33-0.65]$} & 0.000 \\
\hline Undifferentiated carcinoma & 9.9 & 1.43 & {$[1.21-1.70]$} & 0.000 \\
\hline Other $^{\mathrm{b}}$ & 33.5 & 1.42 & {$[1.07-1.84]$} & 0.006 \\
\hline No histology & 1.5 & 1.07 & {$[0.82-1.40]$} & 0.620 \\
\hline \multicolumn{5}{|l|}{ Location } \\
\hline Cardia & 11.7 & 1 & & \\
\hline Fundus & 23.5 & 0.83 & {$[0.70-0.98]$} & 0.025 \\
\hline Corpus & 29.6 & 0.90 & [0.79-1.03] & 0.139 \\
\hline Antrum and pylorus & 27.2 & 0.79 & {$[0.69-0.89]$} & 0.000 \\
\hline More than one site & 9.0 & 1.08 & [0.92-1.27] & 0.345 \\
\hline $\operatorname{NOS}^{c}$ & 16.1 & 1.01 & {$[0.80-1.23]$} & 0.958 \\
\hline
\end{tabular}

Our study is important in that it provides data on the implementation of adjuvant and palliative chemotherapy. As reported in American and European studies [9, 14], there was a progressive increase in the proportion of patients treated. It was only in 2001 that a trial suggested that a benefit could be derived from adjuvant chemotherapy [17]. The results have since been criticized. Recently, the MAGIC trial demonstrated a better survival rate using perioperative chemotherapy [18]. It is too early to evaluate the impact of this study published in 2006. It has been reported that palliative chemotherapy has a beneficial effect on survival [19], but this effect is modest. In our study, there has been a progressive increase in the trectomy, which is related to operative mortality. 
Table 6 Five-year relative survival for gastric cancer by stage and time period

\begin{tabular}{lcccr}
\hline & $1976-1983$ & $1984-1997$ & $1992-1999$ & $2000-2007$ \\
\hline Stage at diagnosis & & & & \\
$\quad$ TNM I & $81.8[62.4-91.9]$ & $80.3[69.9-87.4]$ & $78.6[68.7-85.8]$ & $88.4[74.4-95.0]$ \\
TNM II & $33.5[23.6-43.7]$ & $49.8[39.6-57.5]$ & $44.3[33.9-54.1]$ & $38.2[26.3-50.0]$ \\
TNM III & $16.4[10.4-23.5]$ & $20.2[15.0-26.0]$ & $19.8[14.5-25.6]$ & $32.9[23.9-42.3]$ \\
Advanced $^{\text {a }}$ & $2.6[1.2-5.2]$ & $3.0[1.7-4.9]$ & $3.8[2.3-5.9]$ & $3.7[2.0-6.0]$ \\
\hline
\end{tabular}

${ }^{a}$ TNM stage IV cancer cases and nonresected cancers with no evidence of visceral metastasis

proportion of treated patients since 1992, and nearly half of them were treated during the last study period.

It is well known that stage at diagnosis is the major prognostic factor. The 5-year relative survival was more than $80 \%$ in stage I. It decreased sharply when the entire gastric wall was involved and became poor when lymph nodes were invaded. This finding indicates that significant improvements in prognosis can be achieved by earlier diagnosis. Indeed, the improvement in survival observed during the first three time periods can be matched with the increase in the proportion of early-stage detection and of R0 resections during these periods. Thereafter, improvements in early-stage detection and R0 resection leveled off, and no significant progress in survival was seen.

The prognostic significance of older age and histological type in our study is comparable to the results of other studies [13, 20, 21]. The prognosis was significantly better for lymphoma than for adenocarcinoma, and prognosis was worse for undifferentiated carcinoma than for adenocarcinoma.

In conclusion, this study shows no major improvement in stage at diagnosis or survival of gastric cancer over the past three decades. There was even a decrease in the rate of R0 gastric resection between the 1980-1999 period and the 2000-2007 period, which can be related to better preoperative staging. The lack of improvement in survival also indicates the meager effectiveness of adjuvant and palliative therapies. Improvements in treatment are still required.

Acknowledgments The authors thank all the private and public physicians, specialists, and pathologists for their collaboration, and the National Public Health Institute (InVS) and the National Cancer Institute (INCa) for supporting the Registry.

Conflict of interest None of the authors has any conflicts of interest to declare regarding this study.

\section{References}

1. Boyle P, Ferlay J. Cancer incidence and mortality in Europe, 2004. Ann Oncol. 2005;16(3):481-8.

2. Belot A, Grosclaude P, Bossard N, Jougla E, Benhamou E, Delafosse P, et al. Cancer incidence and mortality in France over the period 1980-2005. Rev Epidemiol Sante Pub. 2008;56:159-75.

3. Verdecchia A, Guzzinati S, Francisci S, De Angelis R, Bray F, Allemani C, et al. Survival trends in European cancer patients diagnosed from 1988 to 1999. Eur J Cancer. 2009;45(6):1042-66.

4. De Vita F, Vecchione L, Galizia G, Di Martino N, Fabozzi T, Catalano G, et al. Perspectives in adjuvant therapy of gastric cancer. Oncology. 2009;77(suppl 1):38-42.

5. WHO. International Classification of Disease for Oncology. Third edition. 2000; Geneva: World Health Organization.

6. Siewert JR, Bottcher K, Roder JD, Busch R, Hermanek P, Meyer HJ. Prognostic relevance of systematic lymph node dissection in gastric carcinoma. German Gastric Carcinoma Study Group. Br J Surg. 1993;80:1015-8.

7. Dickman P, Sloggett A, Hills M, Hakulinen T. Regression models for relative survival. Stat Med. 2004;23:51-64.

8. Allum WH, Powell DJ, McConkey CC, Fielding JW. Gastric cancer: a 25-year review. Br J Surg. 1989;76(6):535-40.

9. Wanebo HJ, Kennedy BJ, Chmiel J, Steele G Jr, Winchester D, Osteen R. Cancer of the stomach. A patient care study by the American College of Surgeons. Ann Surg. 1993;218(5):583-92.

10. Fayçal J, Bessaguet C, Nousbaum J, Cauvin J, Cholet F, Bideau $\mathrm{K}$, et al. Epidemiology and long term survival of gastric carcinoma in the French district of Finistere between 1984 and 1995. Gastroenterol Clin Biol. 2005;29(1):23-32.

11. Lambert R, Guilloux A, Oshima A, Pompe-Kirn V, Bray F, Parkin $\mathrm{M}$, et al. Incidence and mortality from stomach cancer in Japan, Slovenia and the USA. Int J Cancer. 2002;97(6):811-8.

12. Schlemper RJ, Itabashi M, Kato Y, Lewin KJ, Riddell RH, Shimoda $\mathrm{T}$, et al. Differences in diagnostic criteria for gastric carcinoma between Japanese and Western pathologists. Lancet. 1997;349(9067):1725-9.

13. Bouvier AM, Sant M, Verdecchia A, Forman D, Damhuis R, Coebergh JW, et al. What reasons lie behind long-term survival differences for gastric cancer within Europe? Eur J Cancer. 2010;46(6): 1086-92.

14. Dassen AE, Lemmens VE, van de Poll-Franse LV, Creemers GJ, Brenninkmeijer SJ, Lips DJ, et al. Trends in incidence, treatment and survival of gastric adenocarcinoma between 1990 and 2007: a population-based study in the Netherlands. Eur J Cancer. 2010;46(6):1101-10.

15. Le A, Berger D, Lau M, El-Serag HB. Secular trends in the use, quality, and outcomes of gastrectomy for noncardia gastric cancer in the United States. Ann Surg Oncol. 2007;14(9):2519-27.

16. Lepage C, Sant M, Verdecchia A, Forman D, Esteve J, Faivre J. Operative mortality after gastric cancer resection and long-term survival differences across Europe. Br J Surg. 2010;97(2):235-9.

17. Macdonald JS, Smalley SR, Benedetti J, Hundahl SA, Estes NC, Stemmermann GN, et al. Chemoradiotherapy after surgery compared with surgery alone for adenocarcinoma of the stomach or gastroesophageal junction. $\mathrm{N}$ Engl $\mathrm{J}$ Med. 2001;345(10):725-30. 
18. Cunningham D, Allum WH, Stenning SP, Thompson JN, Van de Velde CJ, Nicolson M, et al. Perioperative chemotherapy versus surgery alone for resectable gastroesophageal cancer. N Engl J Med. 2006;355(1):11-20.

19. Webb A, Cunningham D, Scarffe JH, Harper P, Norman A, Joffe JK, Hughes M, et al. Randomized trial comparing epirubicin, cisplatin, and fluorouracil versus fluorouracil, doxorubicin, and methotrexate in advanced esophagogastric cancer. J Clin Oncol. 1997;15(1):261-7.
20. Piessen G, Messager M, Leteurtre E, Jean-Pierre T, Mariette C. Signet ring cell histology is an independent predictor of poor prognosis in gastric adenocarcinoma regardless of tumoral clinical presentation. Ann Surg. 2009;250(6):878-87.

21. Montalban C, Manzanal A, Castrillo JM, Escribano L, Bellas C. Low grade gastric B-cell MALT lymphoma progressing into high grade lymphoma. Clonal identity of the two stages of the tumour, unusual bone involvement and leukemic dissemination. Histopathology (Oxf). 1995;27(1):89-91. 